\title{
IMPLEMENTASI ASUHAN KEPERAWATAN
}

\section{Putri Syalsabila Manullang}

\author{
psbila@gmail.com
}

\section{Latar Belakang}

Asuhan keperawatan adalah suatu pendekatan yang bertujuan untuk memecahkan masalah yang dapat membantu perawat dalam mengatur dan memberikan asuhan keperawatan . Implementasi adalah pengelolaan dari suatu rencana keperawatan yang telah disusun pada tahap perencanaan (Setiadi, 2012).

Implementasi merupakan tahap proses keperawatan dimana perawat memberikan intervensi keperawatan langsung dan tidak langsung terhadap klien. Implementasi keperawatan adalah serangkaian kegiatan yang dilakukan oleh perawat untuk membantu klien dari masalah status kesehatan yang dihadapi ke status kesehatan yang lebih baik yang menggambarkan kriteria hasil yang diharapkan. Pada saat implementasi perawat harus melaksanakan hasil dari rencana keperawatan yang di lihat dari diagnosa keperawatan. Di mana perawat membantu klien dari masalah status kesehatan yang dihadapi kestatus kesehatan yang lebih baik yang menggambarkan kriteria hasil yang diharapkan. Sehingga, dengan proses keperawatan, rasa tanggung jawab dan tanggung gugat bagi perawat itu dapat dimiliki dan dapat digunakan dalam tindakan-tindakan yang merugikan atau menghindari tindakan yang legal. Semua tatanan perawatan kesehatan secara hukum perlu mencatat observasi keperawatan, perawatan yang diberikan, dan respons pasien.

Proses keperawatan adalah salah satu metoda efektif pemecahan masalah yang dilakukan perawat terhadap klien dengan pendekatan metodologi ilmiah. Asuhan keperawatan dapat dipertanggungjawabkan berdasarkan substansi ilmiah yaitu logis, sistimatis, dinamis dan terstruktur (Muhlisin, 2011). Proses keperawatan adalah suatu metode ilmiah yang sistematis dan terorganisir dalam memberikan asuhan keperawatan pada pasien yang berfokus pada respon individu terhadap gangguan kesehatan yang dialami (Manurung, 2011). Penting bagi perawat untuk memahami proses keperawatan. Hal ini bertujuan untuk menunjukkan bahwa seorang perawat adalah seorang tenaga kesehatan profesional yang membedakannya dengan tenaga profesional lainnya.

Asuhan keperawatan merupakan indikator dalam menentukan kualitas pelayanan dari suatu Rumah Sakit. Perawat merupakan profesi yang memberikan pelayanan keperawatan kepada pasien, dimana salah satu aspek terpenting dari kinerjanya adalah pendokumentasian asuhan keperawatan. Kinerja perawat dalam pelayanan keperawatan dipengaruhi oleh beberapa faktor yaitu karakteristik organisasi (kepemimpinan), karakteristik individu (motivasi), dan karakteristik pekerjaan (beban kerja) (Nursalam, 2015). Menurut Robert L. Mathis (2001) faktor yang 
mempengaruhi kinerja yaitu: kemampuan, motivasi, dukungan yang diterima, keberadaan pekerjaan yang mereka lakukan, dan hubungan mereka dengan organisasi.

Adapun teori dalam keperawatan yang digunakan model konsep dalam keperawatan, sehingga model dalam keperawatan itu mengandung sebuah arti aplikasi dari struktur keperawatn itu sendiri yang dapat memungkinkan seorang perawat untuk menerapkan cara dalam bekerja dan batas kewenangan sebagai seorang perawat. Tahap implementasi dimulai setelah rencana tindakan disusun dan ditunjukkan nursing orders untuk membantu klien mencapai tujuan yang diharapkan.

Teknologi pada saat ini yang semakin canggih terutama diantaranya yaitu teknologi dalam kesehatan yang digunakan untuk instansi kesehatan yang sangat berkembang di zaman sekarang ini sangat berdampak sekali pada bidang kesehatan. Yang dapat meningkatkan mutu dan kualitas perawatan kesehatan yang lebih baik karena dapat membantu para instansi ksehatan, seperti dokter, perawatn, dan instansi keperawatan lainnya. Adapun contohnya yaitu nursing management information systems efektif yang dapat menghemat waktu dan sangat berguna dalam assuhan keperawatan (Choi, Yang, \& Lee, 2014).

Proses asuhan keperawatan yang merupakan kewajiban dari seorang perawat dari pasien datang kerumah sakit hingga pasien pulang, yang dimulai dari pengkajian terhadap pasien secara menyeluruh, kemudian menegakkan diagnosa keperawatan dari pengkajian yang telah dilakukan sebelumnya, serta melaksanakan intervensi, implementasi, dan evaluasi dari diagnosa awal yang sudah ditegakkan (Nursalam, 2007).

\section{Metode}

Penulisan kajian artikel ilmiah ini dibuat menggunakan model metode membaca atau literasi, menganalisa serta penelurusan ke berbagai referensi-referensi yang diantaranya yaitu jurnal ( 8 tahun terakhir), buku-buku teks, e-book, dan e-learning. Artikel ilmiah dalam kajian ini telah diatur dan disusun sesuai dengan topik yang mengacu pada sumber-sumber terkait yang berfokus pada implementasi asuhan keperawatan.

\section{Hasil}

Dari referensi dan sumber, hasil analisa yang didapatkan adalah banyaknya perawat yang telah berhasil dalam menerapkan implementasi asuhan keperawatan ini kepada pasien dengan baik, tetapi ada sebagian yang masih kurang baik dalam melakukan implementasi keperawatan kepada pasien. Perawat yang dikatakan baik dalam asuhan keperawatan yaitu perawat yang telah melaksanakan tahap-tahap dalam memberikan asuhan keperawatan kepada pasien , yaitu tahap pengkajian, diagnosa, perencanaan keperawatan, implementasi, dan evaluasi.

Secara garis besar ada tiga kategori dari implementasi keperawatan yaitu: Cognitive implementations, Interpersonal implementations, Technical implementations. 
Implementasi asuhan keperawatan yang efektif adalah memberikan asuhan sesuai dengan yang harus dilakukan. Semakin baik pengetahuan dan pengalaman seorang perawat, maka semakin efektif asuhan yang akan diberikan. Proses Keperawatan yang terkandung dalam Asuhan Keperawatan, tidak hanya bisa digunakan dalam pelayanan keperawatan, lebih dari itu bisa digunakan dalam berbagai tatanan kehidupan, baik dalam manajerial, pendidikan ataupun penelitian.

Implementasi intervensi keperawatan yang berhasil, membutuhkan keterampilan kognitif, interpersonal, dan psikomotor. Proses pelaksanaan implementasi harus berpusat kepada kebutuhan klien, faktor-faktor lain yang mempengaruhi kebutuhan keperawatan, strategi implementasi keperawatan, dan kegiatan komunikasi. (Kozier et al., 1995).

Menurut Hidayat, Proses keperawatan merupakan cara yang sistematis yang dilakukan oleh perawat bersama klien dalam menentukan kebutuhan asuhan keperawatan dengan melakukan pengkajian, menentukan diagnosis, merencanakan tindakan yang akan dilakukan, melaksanakan tindakan serta mengevaluasi hasil asuhan yang telah diberikan dengan berfokus pasa klien, berorentasi pada tujuan pada setiap tahap saling terjadi ketergantungan dan saling berhubungan.

\section{Pembahasan}

Menurut Undang-undang Nomor 38 tahun 2014, keperawatan adalah kegiatan pemberian asuhan kepada individu, keluarga, kelompok, atau masyarakat, baik dalam keadaan sakit maupun sehat. Asuhan Keperawatan adalah suatu proses atau rangkaian kegiatan pada praktik keperawatan yang langsung diberikan kepada klien pada berbagai tatanan pelayanan kesehatan, dalam upaya pemenuhan Kebutuhan Dasar Manusia (KDM), dengan menggunakan metodologi proses keperawatan dan berpedoman pada standar keperawatan,dilandasi kode etik dan etika keperawatan, dalam lingkup wewenang serta tanggung jawab keperawatan. (DPP PPNI, 1999).

Implementasi adalah penerapan atau pelaksanaan. Implementasi juga bisa diartikan sebagai tindakan untuk menjalankan rencana yang telah dibuat. Implementasi ini tidak cuma aktivitas, namun sebuah kegiatan yang direncanakan serta dikerjakan dengan serius dengan berpedoman pada beberapa norma spesifik mencapai maksud kegiatan. Oleh sebab itu, proses tidak berdiri dengan sendirinya namun dipengaruhi juga oleh objek selanjutnya.

Adapun tujuan dari implementasi asuhan keperawatn yaitu membantu klien dalam mencapai tujuan yang telah ditetapkan, yang mencakup peningkatan kesehatan, pencegahan suatu penyakit, peulihan kesehatan dan memfasilitasi koping.

Implementasi asuhan keperawatan adalah kegiatan yang dilakukan seorang perawat untuk membantu seorang pasien terhadap masalah status kesehatan pasien yang dihadapi dengan baik, yang menggambarkan kriteria hasil yang diharapkan.

tiga kategori dari implementasi keperawatan (Craven dan Hirnle, 2000) antara lain: 
a. Cognitive implementations.

Yang merupakan pengajaran atau pendidikan, menghubungkan tingkat pengetahuan klien dengan kegiatan hidup sehari-hari, membuat strategi untuk klien dengan disfungsi komunikasi, memberikan umpan balik, mengawasi tim keperawatan, mengawasi penampilan klien dan keluarga, serta menciptakan lingkungan sesuai kebutuhan, dan lain lain.

b. Interpersonal implementations.

Yaitu koordinasi kegiatan-kegiatan, meningkatkan pelayanan, menciptakan komunikasi terapeutik, menetapkan jadwal personal, pengungkapan perasaan, memberikan dukungan spiritual, bertindak sebagai advokasi klien, dan role model.

c. Technical implementations.

Merupakan pemberian perawatan kebersihan kulit, melakukan aktivitas rutin keperawatan, menemukan perubahan dari data dasar klien, mengorganisir respon klien yang abnormal, melakukan tindakan keperawatan mandiri, kolaborasi, dan rujukan.

Untuk mencapai keberhasilan atau kesuksesan pelaksanaan implementasi keperawatan agar sesuai dengan rencana keperawatan, perawat harus mempunyai kemampuan kognitif (intelektual), kemampuan dalam hubungan interpersonal, dan keterampilan dalam melakukan tindakan. Proses pelaksanaan implementasi harus berpusat kepada kebutuhan klien, faktor-faktor lain yang mempengaruhi kebutuhan keperawatan, strategi implementasi keperawatan, dan kegiatan komunikasi antar perawat dengan pasien. (Kozier et al., 1995).

Dokumentasi pada implementasi asuhan keperawatan didefinisikan sebagai segala sesuatu yang tertulis yang dapat diandalkan sebagai catatan tentang bukti bagi individu yang berwenang. Catatan medis harus mendeskripsikan tentang status dan kebutuhan klien yang komprehensif, juga layanan yang diberikan untuk perawatan klien. Adapun hal-hal yang perlu didokumentasikan pada tahap implementasi asuhan keperawatan ini terdiri atas:

$\checkmark$ Mencatat waktu dan tanggal pelaksanaan.

$\checkmark$ Mencatat diagnosa keperawatan nomor berapa yang dilakukan intervensi tersebut.

$\checkmark$ Mencatat semua jenis intervensi keperawatan.

$\checkmark$ Serta memberikan tanda tangan dan nama jelas perawat satu tim kesehatan yang telah melakukan intervensi kepada pasien.

Implementasi mencakup melakukan, membantu, atau mengarahkan kinerja aktivitas kehidupan sehari-hari, memberikan arahan perawatan untuk mencapai tujuan yang berpusat pada klien, menyelia dan mengevaluasi kerja anggota staf, dan mencatat serta melakukan pertukanran informasi yang relevan dengan perawatan kesehatan berkelanjutan dari klien. Klien mungkin membutuhkan intervensi dalam bentuk dukungan, medikasi, pengobatan untuk kondisi terbaru, edukasi klien-keluarga, atau tindakan untuk mencegah masalah kesehatan dimasa mendatang. 
Implementasi patient safety bertujuan untuk meningkatkan mutu pelayanan kesehatan yang ada dirumah sakit. Pasient safety merupakan upaya-upaya pelayanan yang mengutamakan pada keselamatan pasien. Penekanannya adalah pada pelaporan kejadian yang merugikan pasien, pencegahan terhadap kesalahan medis dan pencegahan perawatan yang dapat merugikan kesehatan, serta keselamatan pasien (Blendon, 2002). Pada tanggal 27 Oktober 2004 WHO meresmikan World Alliance for Patient Safety yang bertujuan untuk mengkoordinasikan aksiaksi global berkaitan dengan keselamatan pasien dan melawan permasalahan-permasalah kerugian pasien yang semakin banyak dilaporkan. Pada saat implementasi perawat harus melaksanakan hasil dari rencana keperawatan yang di lihat dari diagnosa keperawatan. Di mana perawat membantu klien dari masalah status kesehatan yang dihadapi kestatus kesehatan yang lebih baik yang menggambarkan kriteria hasil yang diharapkan. Sehingga, dengan proses keperawatan, rasa tanggung jawab dan tanggung gugat bagi perawat itu dapat dimiliki dan dapat digunakan dalam tindakan-tindakan yang merugikan atau menghindari tindakan yang legal. Semua tatanan perawatan kesehatan secara hukum perlu mencatat observasi keperawatan, perawatan yang diberikan, dan respons pasien.

Implementasi merupakan pelaksanaan dari rencana intervensi keperawatan. Komponen yang ada pada format dokumentasi implementasi pada pemenuhan kebutuhan keselamatan dan keamanan :

a). Nama pasien, umur.

b). Ruangan, kamar, bed.

c). Nomor registrasi, nomor rekam medik.

d). Hari, tanggal, dan waktu.

e). Diagnosa.

f). Tindakan keperawatan dan hasil, respon klien.

g). Paraf dan nama jelas perawat

Konseling adalah metode implementasi yang mebantu klien menggunakan proses pemecahan masalah untuk mengenali dan menangani stres dan yang memudahkan hubungan interpersonal antara klien, keluarganya, dan tim perawatan kesehatan. Ini berjtujuan untuk membantu klien menerima perubahan yang akaan terjadi yang diakibatkan stres berupa dukungan emosional, intelektual, spiritual, dan psikologis. Bukan hanya konseling, Penyuluhan juga termasuk dalam metode implementasi yang digunakan untuk menyajikan prinsip, prosedur, dan teknik yang tepat tentang perawatan kesehatan untuk klien dan untuk menginformasikan klien tentang status kesehatannya.

Adapun konsep dasar dari asuhan keperawatan yaitu Pelayanan kesehatan merupakan sebuah produk jasa. Yang namanya jasa, pasti menginginkan orang lain atau klien puas terhadap layanan yang mereka gunakan. Klien tentunya menginginkan untuk mendapatkan pelayanan terbaik 
dalam pelayanan kesehatan. Dan karena itulah, proses pelayanan kesehatan selalu ingin menampilkan dan memberikan bentuk layanan terbaik untuk setiap tatanan kehidupan klien. Dan sebagai ujung tombak dalam pelayanan kesehatan, perawat berdiri dalam garda paling depan dalam proses pelayanan untuk memberikan pelayanan keperawatan yang berkualitas.

Menurut Ali (1997) proses keperawatan adalah metode asuhan keperawatan yang ilmiah,sistematis,dinamis,dan terus- menerus serta berkesinambungan dalam rangka pemecahan masalah kesehatan pasien/klien,di mulai dari pengkajian (pengumpulan data,analisis data,dan penentuan masalah) diagnosis keperawatan, pelaksanaan, dan penilaian tindakan keperawatan. Asuhan keperawatan di berikan dalam upaya memenuhi kebutuhan klien. Menurut A Maslow ada lima kebutuhan dasar manusia yaitu kebutuhan fisiologis meliputi oksigen,cairan,nutrisi, kebutuhan rasa aman dan perlindungan,kebutuhan rasa cinta dan saling memiliki,kebutuhan akan harga diri dan kebutuhan aktualisasi diri.

Menurut Nurdin Usman, "Implementasi adalah bermuara pada aktivitas, aksi, tindakan, atau adanya mekanisme suatu sistem. Implementasi bukan sekedar aktivitas, tetapi suatu kegiatan yang terencana dan untuk mencapai tujuan kegiatan"(Usman, 2002:70). Tujuan utama implementasi adalah untuk melaksanakan rencana yang telah disusun dengan cermat, baik oleh individu maupun kelompok. Untuk menguji serta mendokumentasikan suatu prosedur kesehatan dalam penerapan rencana atau kebijakan.

\section{Penutup}

a. Kesimpulan

Implementasi merupakan inisiatif dari rencana tindakan untuk mencapai tujuan yang spesifik. implementasi perawat harus melaksanakan hasil dari rencana keperawatan yang di lihat dari diagnosa keperawatan. Tahap pelakasaan dimulai setelah rencana tindakan disusun dan ditunjukkan pada nursing orders untuk membantu klien mencapai tujuan yang diharapkan. Pelaksanaan tindakan keperawatan harus diikuti oleh pencatatan yang lengkap dan akurat terhadap suatu kejadian dalam proses keperawatan. Proses Keperawatan yang terkandung dalam Asuhan Keperawatan, tidak hanya bisa digunakan dalam pelayanan keperawatan, lebih dari itu bisa digunakan dalam berbagai tatanan kehidupan, baik dalam manajerial, pendidikan ataupun penelitian.

\section{b. Saran}

Baik mahasiswa keperawatan maupun tenaga profesi keperawatan harus mampu meningkatkan pemahamannya teerhadap berbagai cara pendokumentasian implementasi keperawatan sehingga dapat dikembangkan dalam tatanan layanan keperawatan. Diharapkan agar perawat bisa menindak lanjuti pendokumentasian tersebut melalui kegiatan asuhan keperawatan sebagai dasar untuk pengembangan kedisiplinan di lingkungan rumah sakit dalam ruang lingkup keperawatan. 


\section{DAFTAR PUSTAKA}

Budiono, Sumirah. (2016). Konsep Dasar Keperawatan. Jakarta : Bumi Medika.

Butar-Butar, J., \& Simamora, R. H. (2016). Hubungan Mutu Pelayanan Keperawatan dengan Tingkat Kepuasan Pasien Rawat Inap di RSUD Pandan Kabupaten Tapanuli Tengah. Jurnal Ners Indonesia, 6(1), 50-63.

Dwi dan Diah Fatmawati. (2016). Beban Kerja Perawat Implementasi Patient Safety di Ruang Rawat Inap. Jurnal Keperawatan Soedirman (The Soedirman Journal of Nursing), Volume 11, No.1, Maret 2016.

Juli, Henni, Panzilion, Selvia, dan Diko. (2019). Implementasi Keperawatan Dengan Pengendalian Diri Klien Halusinasi Pada Pasien Skizofrenia. Jurnal Kesmas Asclepius (JKA),

Volume 1, Nomor 2, Desember 2019.

Putri, Tri, dan Yuyun. (2016). Faktor-faktor yang Berhubungan Dengan Pendokumentasian Asuhan Keperawatan di Rumah Sakit Jiwa. NERS JURNAL KEPERAWATAN, Volume 12, No.2, Oktober 2016, (Hal.131-142).

Retty, Budi, dan Yossie. (2015). Efektivitas Implementasi Asuhan Keperawatan Isolasi Dalam MPKP Jiwa Terhadap Kemampuan Klien. Jurnal Ners, Vol. 10 No. 1 April 2015: 175-182.

Rosari dan Hanny Handiyani. (2019). Manfaat Implementasi Dokumentasi Asuhan Keperawatan Berbasis Komputerisasi Dalam Meningkatkan Mutu Asuhan Keperawatan. Jurnal Ilmiah Kesehatan Pencerah, 08 (2),110-116.

Simamora, R. H. (2005). Hubungan Persepsi Perawat Pelaksana Terhadap Penerapan Fungsi Pengorganisasian Yang Dilakukan Oleh Kepala Ruangan Dengan Kinerjanya Diruang Rawat Inap RSUD Koja Jakarta Utara (Doctoral dissertation, Tesis FIK UI, Tidak dipublikasikan).

Sumarni. (2017). Analisis Implementasi Patient Safety Terkait Peningkatan Mutu Pelayanan Kesehatan di Rumah Sakit. [Jurnal]. Yogyakarta: Universitas Alma Ata.

Supratti dan Ashriady. (2016). Pendokumentasian Standar Asuhan Keperawatan di Rumah Sakit Umum Daerah Mamuju, Indonesia. Jurnal Kesehatan MANARANG, Volume 2, Nomor 1, Juli 2016.

Wahid, Nurul. (2012). Pengantar Dokumentasi Proses Keperawatan. Jakarta : Trans Media Jakarta.

Wahyuningsih dan Atiek. (2018). Tingkat Pengetahuan Dengan Sikap dan Praktik Dalam Implementasi Patient Safety. ADI HUSADA NURSING JOURNAL, VOL.4 NO.1, JUNI 2018.

Wiwin Sulistyawati. (2016). Hubungan Implementasi Asesmen Kompetensi Dengan Pelaksanaan Discharge Planning. Jurnal Care, Vol. 4, No.3, Tahun 2016. 